\title{
Regulating Nanotechnological Applications for Food Contact Materials
}

\author{
André GAZSÓ, Gloria Elisabeth ROSE, Anna PAVLICEK and Sabine GRESSLER*
}

\section{Summary}

Nanomaterials can improve the properties of food contact materials. Innovations of this kind are of particular interest for food packaging made out of plastic materials. The purpose of their use is to improve food storage and so to guarantee both freshness and quality. A further goal is to improve the technical properties of materials in order to make them sturdier, more resistant to abrasion, and easier to process. Food contact materials are subject to a number of EU consumer protection regulations. Nanomaterials require authorisation by the European Food Safety Authority (EFSA), the body responsible for assessing their safety. For nanomaterials authorised for use in the EU, specifications and restrictions are laid down in order to prevent consumers being exposed to them or to keep exposure as low as possible, and so to rule out any danger to health. At the end of the product lifetime, workers of recycling and waste treatment facilities may be exposed to higher levels of ultrafine particles, or particulate matter may be released unintentionally. To date, however, it has not been demonstrated that recycling polymers containing nanomaterials leads to any increased exposure of employees. With regard to environmental protection, little is known at present about the specific behaviour of nanomaterials and composites during waste treatment processes. There is also a need for comprehensive research on how far nanomaterials can be recycled, in order to develop sustainable nanotechnology.

The term "food contact materials" (FCMs) covers a large number of materials and objects that can come into contact with food. The objects include dishes, cutlery, saucepans, frying pans, drinking glasses, garlic presses, spatulas, and coffee machines. But all packaging materials, storage containers and processing machinery used in the food industry also belong to this extensive and important category of utensils covered by food law. Not counted among food contact materials are public and private water supply installations that are legally required to remain in a fixed location, antiques, and coating materials that are not separate from the foodstuff and are consumed along with it. Objects that can come into contact with food can be made of a range of materials, for example metal, ceramics, glass, or plastic materials.

* Institute of Technology Assessment, Austrian Academy of Sciences, Vienna, Austria. Please send inquiries to agazso@oeaw.ac.at. 


\section{EU REGULATION}

For the purposes of consumer protection, FCMs are subject to a number of regulations. The framework directive is Regulation (EC) No 1935/2004, which is based on the principle that materials and objects intended to come into direct or indirect contact with food must be sufficiently inert. The purpose is to exclude any possibility of materials getting into food in quantities that would pose a risk to human health. The regulation also forbids any unacceptable change in the composition of food and any adverse effect on its smell, taste, colour, or appearance caused by a food contact material. ${ }^{1}$

The framework regulation also applies to what are known as "active" and "intelligent" FCMs. The purpose of "active FCMs" is to prolong the shelf life of a packaged foodstuff, or to preserve it in a certain condition or improve that condition. They contain components which emit materials that are taken up by the packaged food or the environment surrounding it, or can absorb materials from the foodstuff or its environment. "Intelligent FCMs" is a term used to refer to materials and objects which monitor the condition of a packaged foodstuff or of the environment surrounding it. These can include sensors which monitor and display, for example, the temperature of a foodstuff. At present there are a number of international research projects in progress for the purpose of developing such "intelligent" packaging materials for future use. ${ }^{2}$ In addition to the framework regulation, Commission Regulation (EC) No 450/2009 3 contains special requirements for the marketing of "active" and "intelligent" FCMs. They must undergo a safety assessment and an authorisation procedure. This regulation states explicitly that possible risks arising from nanoparticles must be assessed on a caseby-case basis, as the chemical and physical properties of these particles differ fundamentally from those of materials with larger structures. Until May 2017, no nanomaterial had been authorised for "active" or "intelligent" FCMs in the EU.

Plastic materials are another group of materials and objects for which requirements already exist in the EU under the terms of Commission Regulation (EU) No 10/2011; nanomaterials are already in use here. The only materials that may be employed intentionally in the manufacture of plastic coatings in materials and objects are those listed on what is known as the "Union list", contained in Annex 1 of this regulation. Materials with a nanostructure may only be used when they are explicitly permitted and appear on the "Union list". The European Food Safety Authority (EFSA) carries out the safety assessment required for permission to be granted. The Regulation does not contain any definition of what exactly is meant by "material with a nanostructure". However, the

\footnotetext{
1 Regulation (EC) No 1935/2004 of the European Parliament and of the Council of 27 October 2004 on materials and articles intended to come into contact with food and repealing Directives 80/590/EEC and 89/109/EEC.

2 E Berghofer, and R Schönlechner, "Detektion und Analyse von Lebensmitteln. Part 6 of 'Neue Verfahren und Techniken bei der Lebensmittelherstellung und Lebensmittelversorgung"” (2015) Bundesministerium für Gesundheit, available at <www.bmgf.gv.at/cms/home/attachments/0/5/0/CH1176/CMS1435845259856/6-trends-detektionlangfassung_web.pdf $>$.

3 Commission Regulation (EC) No 450/2009 of 29 May 2009 on active and intelligent materials and articles intended to come into contact with food.

4 Commission Regulation (EU) No 10/2011 of 14 January 2011 on plastic materials and articles intended to come into contact with food.
} 
"novel foods" regulation ${ }^{5}$ contains a definition that applies to all EU food legislation. The "Union list" contains 11 materials that fall under the definition of a "technically manufactured nanomaterial" in the sense of the "novel foods" regulation.

Any food that is not consumed immediately after manufacture requires packaging. Packaging is intended above all to protect food against dirt, oxygen, light or ultraviolet rays, microorganisms and moisture, and it also needs to be safe to use and cheap to produce. In addition, it should be light, able to stand up to processing, filling, storage and transport, and to present no problems for waste disposal or recycling. Many plastic materials, those known as polymers, meet these requirements. The materials most frequently used for FCMs are polyolefins, for example polypropylene (PP) and a range of kinds of polyethylene, and also polyethylene terephthalate (PET), polystyrene (PS), and polyvinyl chloride (PVC). ${ }^{6}$ However, there are also problems with plastic materials: gases can permeate them, and they have low resistance to high temperatures and mechanical load. For this reason, additional materials known as additives or fillers are added to polymers in order to improve their properties. Nanomaterials, used as functional fillers, are playing an increasingly significant role here. For example, titanium nitride can improve the thermal and mechanical properties of PET bottles. ${ }^{7}$

\section{NANOMAterials For FCMs}

The following nanomaterials have been approved for use in FCMs made of plastic materials; these have a range of functions, and precise specifications have been laid down to protect consumers.

Silicon dioxide $\left(\mathrm{SiO}_{2}\right)$, silanated: $\mathrm{SiO}_{2}$, silanated, has been permitted since 1999 in the EU, without any restrictions, as an additive for all kinds of plastic materials. It is used, for example, to improve the stiffness and tensile strength of a polymer and to reduce its permeability to oxygen. $\mathrm{SiO}_{2}$ can also be used for barrier layers that are added to foil by vapour deposition. Such multi-layer foils have been used for some time for food packaging, for example for potato crisps and cheese. ${ }^{8}$

Kaolin: Kaolin, which is also known as china clay, is a white stone; its main component is kaolinite, which results from the erosion of feldspar. ${ }^{9}$ Kaolin is treated with a surface layer of polyacrylic acid and sodium salt in order to make it easier to disperse the substance evenly. Kaolin platelets are less than $100 \mathrm{~nm}$ thin, and they are incorporated in a concentration of up to $12 \%$ into an inner layer made of ethylene vinyl

\footnotetext{
5 Regulation (EU) 2015/2283 of the European Parliament and of the Council of 25 November 2015 on novel foods, amending Regulation (EU) No 1169/2011 of the European Parliament and of the Council and repealing Regulation (EC) No 258/97 of the European Parliament and of the Council and Commission Regulation (EC) No 1852/2001.

6 NanosafePACK, "Development of a best practice guide for the safe handling and use of nanoparticles in packaging industries", D1.1. Report on the nanoclay and metal oxide nanoparticles employed on the packaging industry (2012), available at <www.nanosafepack.eu/sites/default/files/news-download-files/NANOSAFEPAK_D1.1_Report\%20on $\% 20$ Nanoclays\%20and\%20MONPs_r1.pdf $>$.

7 M Xanthos, Functional Fillers for Plastics (Wiley 2010).

8 Bayerisches Landesamt für Gesundheit und Lebensmittelsicherheit (LGL), Nanomaterialien in Lebensmitteln und Verbraucherprodukten. Anwendungsbereiche, Analytik, rechtliche Rahmenbedingungen. (2012) Vol 24 of the series Gesundheit und Umwelt, available at < www.lgl.bayern.de/publikationen/doc/nanomaterialien_lebensmittel_produkte. pdf $>$.

9 See <en.wikipedia.org/wiki/Kaolinite >.
} 
alcohol copolymer $(\mathrm{EVOH})$ in a multi-layer structure. This layer functions as a gas barrier in FCMs for drinks, sauces, dressings, and sausages, and also in pet food.

Carbon black: Carbon black consists of nano-scale carbon particles that form larger aggregates and agglomerates. The substance is sold in powdered form, and has been in use for decades for a range of applications including car tyres, cosmetics, as black pigment, and also as protection against UV rays for FCMs made of plastic materials.

Titanium nitride nanoparticles: Titanium nitride nanoparticles are used as an additive for FCMs made of PET (for example bottles), in order to improve the thermal properties of the plastic material. ${ }^{10}$ The substance was evaluated by the EFSA in 2008 to establish whether it could be used in PET bottles. An application to have its use extended to include foil made of PET was considered in 2012. ${ }^{11}$ Titanium nitride nanoparticles are approximately $20 \mathrm{~nm}$ in size as primary particles. When they are incorporated into PET, agglomerates with a diameter of approximately 100-500 nm are formed. Titanium nitride is chemically inert and does not dissolve in any of the food simulants that have been tested.

Copolymers in nanoform: Copolymers of butadiene, ethyl acrylate, methyl methacrylate, and styrene may be used in the EU in a concentration of up to $10 \% \mathrm{w} / \mathrm{w}$ as an additive (impact modifier) in non-plasticised PVC. ${ }^{12}$ Copolymers are made up of various kinds of monomer units, and under the terms of Regulation (EU) 10/2011 only certain monomers may be used for FCMs made of PVC. Since these monomers are incorporated into the polymer matrix having no reactive functional chemical groups, either no migration or only very limited migration of nanoparticles from the FCM into the food can be expected.

Montmorillonite clay (nanoclay): Nano-scale montmorillonite is a natriumaluminium silicate and is also known as nanoclay, since these layer silicates have at least one nanometer-scale dimension. The platelets are no more than between 1 and a few nanometers thick, and vary from several hundred to thousands of nanometers in length. Montmorillonite is a major component of bentonite (60-80\%). The literature indicates that nanoclay is currently the nanomaterial in most frequent international commercial use, with a market share of about $70 \%{ }^{13}$ Even small amounts of nanoclay $(1-5 \% \mathrm{w} / \mathrm{w})$ can improve the capacity of FCMs to function as a gas barrier, since gases and aroma materials (carbonic acid, food aromas, etc) must take a longer route between the platelets positioned parallel to the surface of the plastic material matrix. ${ }^{14}$ The gas barrier functions, for example, to prolong the shelf life and improve the aroma stability of food. In order to incorporate layer silicates like montmorillonite evenly into a plastic material matrix, however, the platelets must first be separated from one another and have their surfaces modified, since they would otherwise agglomerate immediately during

10 DaNa, "Titannitrid - Materialinfo", available at < nanopartikel.info/nanoinfo/materialien/titannitrid/materialinfotitannitrid $>$.

11 EFSA, "Scientific Opinion on the safety evaluation of the substance titanium nitride, nanoparticles, for use in food contact materials" (2012) 10(3) EFSA Journal 2641, < onlinelibrary.wiley.com/doi/10.2903/j.efsa.2012.2641/epdf > .

12 Impact modification refers to the modification of a material in order to improve its impact strength or impact resistance: see < www.chemgapedia.de/vsengine/glossary/de/schlagz_00228hmodifizierung.glos.html > .

13 K Majeed et al, "Potential materials for food packaging from nanoclay/natural fibres filled hybrid composites" (2013) 46 Materials and Design 391.

14 C Silvestre et al, "Food packaging based on polymer nanomaterials" (2011) 36 Progress in Polymer Science 1766. 
processing. This surface modification is usually carried out by means of quaternary ammonium compounds, which turn the hydrophilic silicate surface into a hydrophobic (organophilic) one. Internationally, nanoclay is used in multi-layer packaging, for example in bottles for carbonated drinks (beer, soft drinks) and thermoformed plastic containers. ${ }^{15}$ The use of montmorillonite has been permitted in the EU since May 2017.

Zinc oxide nanoparticles: The use of zinc oxide in nanoparticulate form as an UVabsorber has been permitted in the EU since 2016, both uncoated and, in order to improve its dispersive properties, coated with a silane. The substance is used in powdered form. Nanoparticles can be found in the final polymer, but mostly in aggregated form. Migration tests showed that zinc ions, but no nanoparticles, were released from the FCM into the test solutions. ${ }^{16}$ These release tests thus indicate that, due to the effects of the environment, zinc ions are more likely to become detached from the nano-zinc oxide polymer than whole nanoparticles. However, the quantity released remains below the tolerable upper intake level (UL value) of $25 \mathrm{mg}$ per person per day recommended by the EU's Scientific Committee on Food. ${ }^{17}$ Nevertheless, in combination with zinc ion intake through food, it is quite possible for this level to be exceeded.

Other nanomaterials not permitted in the EU: A number of further nanomaterials are mentioned in the literature that are used in FCMs, but which are not (yet) permitted in the EU. ${ }^{18}$ These include titanium dioxide $\left(\mathrm{TiO}_{2}\right)$, which can be incorporated into polymers as an UV-absorber or to make use of its anti-microbial effect. There is also a discussion about the possibility of adding nanoparticles of calcium carbonate $\left(\mathrm{CaCO}_{3}\right)$, which can improve the strength and thermal resistance of plastic materials, to FCMs. On the international market (eg in the USA and Asia) FCMs containing nanosilver ${ }^{19}$ are also in use (eg for storage containers and chopping boards); the antimicrobial effect of this substance is said to prolong the shelf-life of food.

\section{CONSUMER PROTECTION}

There can only be a danger to consumers' health from nanomaterials if they are exposed to them, that is to say if the nanomaterial migrates into a foodstuff or drink, for example from the packaging. All nanomaterials permitted for use in FCMs in the EU therefore have to undergo a safety test in which, using standardised test methods, it is established whether such a migration is possible. A range of food simulants, for example alcohol or acid, are used to test the release behaviour of the substance. However, the testing methods that are laid down and standardised in the EU are not validated for nanomaterials. It is a major undertaking to demonstrate the presence of nanoparticles

\footnotetext{
15 Silvestre et al, supra, note 14.

16 EFSA, "Safety assessment of the substance zinc oxide, nanoparticles, for use in food contact materials" (2016) 14 (3) EFSA Journal 4408, available at < onlinelibrary.wiley.com/doi/10.2903/j.efsa.2016.4408/epdf > .

17 EFSA, "Tolerable upper intake levels for vitamins and minerals" (2006) Scientific Committee on Food, Scientific Panel on Dietetic Products, Nutrition and Allergies, available at <www.efsa.europa.eu/sites/default/files/efsa_rep/ blobserver_assets/ndatolerableuil.pdf $>$.

18 For an overview, see NanosafePACK, supra, note 6.

19 See NanoTrust Dossier Nr. 010en, November 2010: "Nanosilver”, < epub.oeaw.ac.at/0xc1aa5576_0x0024c7a6. pdf $>$.
} 
in food, as it is very difficult to distinguish quantitatively between nanoparticles that have been released and the ions produced as they dissolve. Such difficulties lead to some uncertainties, and so make it harder to interpret migration tests with nanomaterials. In many cases, the methods used in scientific studies are not adequately described. ${ }^{20}$

Where nanomaterials permitted in the EU are concerned, specifications for and restrictions on use have been laid down in order to ensure that consumers are not exposed to the materials or that, if they are, the exposure is as low as possible. For example, a plastic material layer into which kaolin has been incorporated must be prevented by means of an additional barrier layer from coming into direct contact with a foodstuff. In general, no migration of nanoparticles permitted in the EU for contact with food into food simulants, has been determined either by the EFSA or by other bodies. ${ }^{21}$ If migration does occur, it has been found to be negligible in terms of any health risk. As already mentioned, though, it is possible for ions to be released from some nanomaterials, for example zinc oxide, nanoclay, and nanosilver, and for these to migrate into food. It is therefore very important that when the risks of such nanocomposites are assessed, such processes also have to be considered. At this point one must also mention the fact that the migration values for separated ions are very specific to the nanomaterial, and can vary considerably depending on where they are actually being used. The fundamental principle is that the limits that are laid down or recommended for intake through food, for instance, should not be exceeded. In an acidic environment, for example, it is possible for aluminium ions to be released from nanoclay. Tests of plastic bags for food sold in shops have shown that both aluminium ions and aluminium nanoparticles can be released. However, the quantity is very low, below the EFSA's tolerable weekly intake (TWA) level of $1 \mathrm{mg}$ of aluminium per kilo of a person's body weight. ${ }^{22}$

The chemical substances used to treat the surfaces of nanoparticles are also a relevant consideration for possible health risks. If, for example, a nanoclay is to be incorporated into a polymer matrix, it is always necessary - except in the case of polyvinyl alcohol to use a quaternary ammonium compound (QAC) as a "mediator", since otherwise the hydrophilic clay will not be satisfactorily incorporated into the hydrophobic plastic material. The nanoclay and the QAC, as the organic modifier, form a unit that cannot be separated again without special chemical processes. However, tests have shown that under certain conditions the compound of plastic material, nano-scale additive and QAC can once again break down. ${ }^{23}$ Since QACs have lipophilic properties, there is a particular risk of migration from food packaging where the packaged food is fatty. Unsuitable plastic materials (eg polyamide) can also be weakened by acidic foods, and there is a possibility of QAC migration into the foodstuff here too. In order to estimate how likely

\footnotetext{
20 Food Standards Australia New Zealand, "Nanotechnologies in Food Packaging: an Exploratory Appraisal of Safety and Regulation. ToxConsult Pty carried out for FSANZ" (2016), available at <www.foodstandards.gov.au/ publications/Documents/Nanotech\%20in\%20food\%20packaging.pdf $>$.

21 ibid.

22 Y Echegoyen et al, "Nanoclay migration from food packaging materials" (2016) 33(3) Food Additives \& Contaminants: Part A.

23 BfR, Freisetzung von Nanomaterialien aus Kunststoffen. Untersuchungen von polymeren Modellwerkstoffen und deren nanoskaligen Füllstoffen (2015), available at < mueef.rlp.de/fileadmin/mulewf/Themen/Umweltschutz/ Gesundheitlicher_Umweltschutz/Freisetzung_von_Nanomaterialien_aus_Kunststoffen.pdf $>$.
} 
this is, one therefore needs to know exactly what the food to be packaged contains; in particular, information about its polarity and lipophilic properties is crucial. One way to minimise the release of QAC and thus prevent consumers' health being endangered is to ensure that the treated plastic layer does not come into direct contact with the foodstuff. The example of a nanomaterial with a surface layer modified by QAC shows that toxicity depends not only on the particle itself but also on its surface coating. A comprehensive survey of the literature on pollution caused by QACs also stresses that they are extremely toxic for aquatic organisms and take a long time to degrade biologically. ${ }^{24}$ Plastic packaging that is thrown away is exposed to the weather, which means that QACs can be released from the polymer matrix and get into waters. Safety testing of nanomaterials for FCMs permitted in the EU also extends to substances used to modify the surfaces of such materials. The only substances that may be used for this purpose are those that are themselves permitted, and/or those for which a specific migration limit has been laid down, for example montmorillonite.

\section{SAFETY DURING WASte Disposal}

Although we know a considerable amount about potential effects on health when polymers containing nanomaterials (nanocomposites) are in use, not much research has been done so far on possible effects on the environment during waste disposal. EU regulations only relate to health risks during use. Dangers to the environment or to human health during waste disposal are not relevant to whether or not a substance is permitted. A survey of the literature carried out by the Organisation for Economic Cooperation and Development (OECD) points out, for example, that nano-scale additives in PET bottles can be released again when the bottles are recycled or regranulated. ${ }^{25}$

Recycling and waste treatment facilities may expose their workers to higher levels of ultrafine particles or particulate matter, and this may also cause nanomaterials to be released unintentionally as a result of mechanical or chemical stress. ${ }^{26}$ To date, however, it has not been demonstrated that recycling polymers containing nanomaterials leads to any increased exposure of workers. In order to rule out any increase in workplace pollution, it would be necessary to carry out a larger number of studies and to measure levels of exposure in workplaces.

Initial laboratory tests, for example tests on polymers containing CNTs, have shown that no increased exposure to individual CNT fibres occurs when these polymers are ground or crushed. ${ }^{27}$ Another study came to similar conclusions for epoxy resin and

\footnotetext{
24 C Zhang et al, "Quaternary ammonium compounds (QACs): a review on occurrence, fate and toxicity in the environment" (2015) Sci Total Environ, 518-519, 352-62.

25 OECD, "Recycling of Waste Containing Nanomaterials" (2015), ENV/EPOC/ WPRPW(2013)2/FINAL, available at $<$ www.oecd.org/officialdocuments/publicdisplaydocumentpdf/?cote=ENV/EPOC/WPRPW(2013)2/ FINAL\&docLanguage $=$ En $>$.

26 J Struwe and E Schindler, "Bedeutung von Nanomaterialien beim Recycling von Abfällen", Arbeitspapier 270 (Hans-Böckler-Stiftung 2012).

27 P Boonruksa et al, "Characterization of Potential Exposures to Nanoparticles and Fibers during Manufacturing and Recycling of Carbon Nanotube Reinforced Polypropylene Composites” (2016) 60(1) Annals of Occupational Hygiene 40.
} 
polycarbonate compound materials containing CNTs. ${ }^{28}$ This study also found that the dust released consists of larger agglomerates in different forms, but never of single released nanoparticles. However, a study that simulated abrasion processes has shown, by using electron microscopy, that material abraded from polymer composites contained a significant proportion of individual CNTs and CNT agglomerates. ${ }^{29}$ All these studies, though, agreed that any potential release depends very much on the actual application, on the carrier matrix itself, and on the processes involved, for example abrasion, crushing, grinding, and so on. Other studies that simulated the ageing processes of nanocomposites have already attempted to standardise testing protocols as a way of making it easier to compare such studies and to make their findings more conclusive. ${ }^{30}$ Nevertheless, significantly more studies would be needed in order to draw general conclusions in the field of FCMs.

With regard to questions of environmental protection, we know just as little at present about the specific behaviour of nanomaterials and composites during waste treatment processes. There are still large gaps in our knowledge of the ultimate environmental fate of nanomaterials that were originally processed in FCMs or composite materials (that is to say knowledge of exact application and input quantities, form, possible transformation processes, toxic endpoints, sinks, etc). In general, there is a lack of comprehensive studies of the recyclability and usability for energy recovery of composite materials, which can only be re-used as FCMs in some exceptional cases, for example PET bottles. At the moment, the subject about which we know least is the precise role of nanoscale additives and filler materials in composite materials during solid waste treatment processes and landfilling.

\section{Conclusion}

Nanomaterials can significantly improve the properties of plastic materials, and this is why materials known as "nanocomposites" are increasingly interesting for manufacturers, especially for food packaging. Nanomaterials used in food contact materials in the EU require authorisation, and the EFSA is responsible for assessing their safety. This is to ensure that nanomaterials do not pose any danger to the health of consumers. At present, little is known about the environmental behaviour of nanomaterials during the end of life phase of FCMs. Nor have many studies been carried out to investigate the possible release of nanoscale additives during waste treatment processes or the question of the exposure of workers during such processes. Further studies and exposure assessments are needed here. If nanotechnology is to be made sustainable there is a need to ensure that, in the framework of a circular economy, plastic materials with nano-scale additives can also be recycled or used for energy recovery in a secure way.

28 D Bello et al, "Exposure to nanoscale particles and fibers during machining of hybrid advanced composites containing carbon nanotubes" (2009) 11(1) Journal of Nanoparticle Research 231.

29 L Schlagenhauf et al, "Release of Carbon Nanotubes from an Epoxy-Based Nanocomposite during an Abrasion Process" (2012) 46(13) Environmental Science \& Technology 7366.

30 W Wohlleben et al, "NanoRelease: Pilot interlaboratory comparison of a weathering protocol applied to resilient and labile polymers with and without embedded carbon nanotubes" (2017) 113 Carbon 346; W Wohlleben et al, "Release from nanomaterials during their use phase: combined mechanical and chemical stresses applied to simple and multi-filler nanocomposites mimicking wear of nano-reinforced tires" (2016) Environmental Science: Nano 3, 1036. 